taking account of it. Consequently, what I called white paper, changed, grew dimmer. And this afternoon what's happening is not that I realise this with my intelligence, but that the whiteness of the paper rushes towards my eyes, and my eyes embrace the whiteness like a long-lost friend.

I'm writing on the paper with black ink. And blacks (as distinct from dark greys, dark blues or greens or browns) have acquired more weight, are heavier. Other colours flare or recede or penetrate but blacks look as though they have been deposited. Laid on top of. And this connects with their weight. The black of a natural substance - such as ebony or obsidian or chromite - is never pure black; other colours hide within it. The laid-on blacks are all man-made.

Before the operation, I made a coloured drawing of a flower - a blue pansy. I did so with the idea of making another drawing of the same flower after the operation

Neither drawing is a copy. Both of course are interpretations of what I saw. They didn't come direct from the retinas of my eyes. Yet the difference between them is, I reckon, similar to the difference between what I perceived before and after the removal of the cataract.

When I compare them now it is as if in the first drawing I was faithfully noting down a sequence of musical notes without being able to hear the vibrations of their physical sounds. In the second drawing the vibrations of those notes were there before my eyes.

The structure and form of the flower is unchanged, as is the botanical logic of its colouring. What has changed is the intimacy of its colouring. Its colours have become naked before my eyes.

After this operation, unlike the first, the treated eye began, an hour or two after the intervention, to hurt and this continued for about a day. With mild painkillers it was quite tolerable. The passage through this small pain was inseparable from my journey towards a newly visible world. I emerged from the pain at the threshold of a new visibility.

A surgical intervention to remove cataracts gives back to the eyes much of their lost talent. Talent, however, invariably implies a certain amount of effort and endurance as well as grace and benefit. And so the new visibility represented for me not only a gift but an achievement. Principally the achievement of the doctors and nurses who carried out the intervention, and also, to some small degree, the achievement of my own body.

The pain made me aware of this.

When you open a dictionary and consult it, you refind, or discover for the first time, the precision of a word. Not only the precision of what it denotes, but also the word's precise place in the diversity of the language.

With both cataracts removed, what I see with my eyes is now like a dictionary which I can consult about the precision of things. The thing in itself, and also its place among other things.

I'm far more aware of comparative scale: the small becomes smaller, the large larger, the immense more immense. And the same is true, not only of things, but of spaces. The small becomes more intimate, the large more extensive. And this is because details - the exact grey of the sky in a certain direction, the way a knuckle creases when a hand is relaxed, the slope of a green field on the far side of a house, such details reassume a forgotten significance.

The unstartling heterogeneousness of the existent has marvellously returned. And the two eyes, portcullises removed, again and again register surprise.

\section{John Berger}

\section{Acknowledgements}

Dedicated with gratitude to Professor Baudouin, Dr Dupont-Monod, and their team at the hospital at Quinze-Vingts, Paris.

DOI: 10.3399/bjgp10X509766

\section{COMMENTARY}

Writer and artist, John Berger, is a global treasure. In 1972, he won the Booker Prize for his novel $G$ and in December 2009 he was awarded the Golden Pen Award for a Lifetime's Distinguished Service to Literature. Back in 1967, in collaboration with the photographer, Jean Mohr, he produced what is considered by many to be the best book ever written about general practice. A Fortunate Man is an account of the life and work of a single-handed GP in a deprived rural area in the Forest of Dean. What is absolutely remarkable about the book is that it demonstrates an understanding of the transactions of general practice care which holds true to this day and yet it was written from outside general practice by a writer and a photographer who simply observed the work of a doctor over the course of a few weeks. It is an extraordinary achievement of empathic imagination. One of the legacies of this enduringly wonderful book is that John Berger has now offered this remarkable description of his recent experience of undergoing cataract surgery, to be distributed as widely as possible for patients facing the same procedure. We will be making it freely available on our website for downloading.

\section{Alec Logan}

DOI: 10.3399/bjgp10X502227 